\title{
БАРЬЕРНЫЕ КАЧЕСТВА ПЕСКОВ СЕВЕРНОГО И ЦЕНТРАЛЬНОГО ВЬЕТНАМА. СОРБЦИЯ ЭМУЛЬСИИ МОТОРНОГО МАСЛА
}

\author{
А. А. Яковлева, Ч. Т. Нгуен

\begin{abstract}
АРИАДНА АЛЕКСЕЕВНА ЯКОВЛЕВА - доктор технических наук, профессор, Иркутский наииональный
\end{abstract} \\ исследовательский технический университет.E-mail: ayakovistu@таil.ru.
}

ЧУНГТХУЙ НГУЕН-аспирант, Иркутский национальный исследовательский технический университет. E-mail: nguyentrungthuy_irk@mail.ru.

664074, Россия, г. Иркутск, ул. Лермонтова, 83. Иркутский наџиональньий исследовательский технический университет.

С изелью изучения физико-химических закономерностей сорбиии нефтепродуктов в ситуации розлива на почву исследованы 3 образиа песков с берегов рек Северного и Центрального Вьетнама и один образеи песка с берега залива Бакбо. Рассматриваемые пески имеют различные кристаллохимические свойства и отличаются по гранулометрическому составу. Для имитации загрязнения использовали водные эмульсии моторного смазочного масла. В ходе исследования рассматривали перенос нефтесодержащей эмульсии через слои песка различной высоты. Способность песка к удержсиванию маслянистых фракиий оценивали по разности между исходной концентрачией эмульсии и концентрацией после фильтрования через слой сорбента, используя флуориметрический метод анализа. Для характеристики способности песков к накоплению органических фракиий проведен анализ ИК-спектров поверхности образиов до и после контакта с нефтепродуктами. Результаты коллоидно-химических исследований свидетельствуют, что углеводородные фрагменты моторного смазочного масла образуют устойчивые пленки на поверхности частии песка. Нефтеудерживание зависит от кристаллохимических и гранулометрических свойств песков. Оно выме у квариевых мелкозернистых песков и идет на убыль с появлением в составе песка 10-11 \% корунда, с укрупнением частии и снижением однородности состава. При высоте слоя песка в 8 см накопление нефттяных фракций в песках достигает 85-90\%. Полученные данные свидетельствуют, что пески Северного и Центрального Вьетнама имеют достаточно высокую удержсивающую способность в отномении нефтесодержащей эмульсии и могут выполнять функиию природных барьеров для защиты нижележащих слоев от проникновения маслянистых загрязнителей.

Ключевые слова: песок, нефтепродукты, моторное масло, экологические барьеры, сорбция.

\section{BARRIER QUALITIES OF THE SANDS OF NORTHERN AND CENTRAL VIETNAM. SORPTION OF THE MOTOR OIL EMULSION}

\author{
A.A. Yakovleva, T. T. Nguyen \\ 664074, Russia, Irkutsk, str. Lermontov 83. Irkutsk National Research Technical University.
}

In order to study the physicochemical regularities of the sorption into the soil of oil products in the situation of bottling, 3 samples of sand from the banks of the rivers of North and Central Vietnam and one sample of sand 
from the coast of the Bay of Bacbo were studied. The sands under consideration have different crystal chemical properties and differ in their granulometric composition. Aqueous emulsions of motor lubricating oil were used to simulate contamination. In the course of the study, the transfer of an oil-containing emulsion through sand layers of different heights was considered. The ability of sand to retain oily fractions of the emulsion was assessed by the difference between the initial concentration and the concentration after filtration through a sorbent layer, which were obtained using the fluorometric method. To characterize the ability of sands to accumulate organic fractions, the FTIR spectra of the surface of samples before and after contact with oil products were carried out. The results of colloidal chemical studies indicate that hydrocarbon fragments of lubricating motor oil form stable films on the surface of sand particles. Oil retention depends on the crystal-chemical and granulometric properties of the sands. It is higher in quartz fine-grained sands and decreases with the appearance of 10-11\% corundum in the sand, with the enlargement of particles and a decrease in the uniformity of the composition. At the height of the sand layer of $8 \mathrm{~cm}$, the accumulation of oil fractions in the sands reaches up to 85-90\%. The data obtained indicate that the sands of North and Central Vietnam have a sufficiently high retention capacity for oil-containing emulsion and can serve as natural barriers to protect the underlying layers from the penetration of oily pollutants.

Key words: sand, petroleum products, motor oil, ecological barriers, sorption.

\section{Введение}

Загрязнение окружающей среды нефтепродуктами является крайне опасным явлением, угрожающим флоре, фауне и здоровью населения [1-5]. Особая ситуация связана с загрязнением прибрежных грунтов открытых бассейнов (рек, озер, морей) и близко лежащих подземных вод. Попадая в грунтовые воды, нефтепродукты могут приникать в нижележащие слои или выходить на поверхность и стать причиной опасных ситуаций. Розливы различных нефтепродуктов, сточные воды и выбросы, содержащие водонефтяные эмульсии, оказывают негативное воздействие на биоту прибрежных областей и водных бассейнов [6-12].

Техногенному воздействию в большинстве случаев подвергается прибрежные грунты, представленные глинами, песками или более крупными минеральными агрегациями типа валунов, гальки, скал и т.п. Находящиеся вблизи движущейся воды, будь то течение реки или морской прилив, прибрежные грунты как элементы литосферы принимают на себя важную роль биорегулятора в процессах установления экологического равновесия.

От нативной способности песков к фильтрации и накоплению поллютантов зависит, каким будет перераспределение загрязняющих веществ и несколько оно опасно для окружающей среды.

В задачи наших исследований входит рассмотрение загрязнения прибрежных песков моторными маслами.

Известно, что одним из основных потребителей моторных масел является автомобильный транспорт, причем, несмотря на постоянное совершенствование двигателей и уменьшение удельного расхода, потребление моторных масел постоян- но растет [3, 10, 11, 13, 14]. Такое возрастание ведет к неизбежному обострению антропогенного угнетения окружающей среды.

Принятие новых, более строгих норм по защите природы требует обоснования и всестороннего изучения экологических проблем, связанных в частности с ситуациями розлива нефтепродуктов на почвы [2, 3, 15-17].

В работе использованы пески с берегов вьетнамских рек Хонга (А), Тхубон (Б), Тхачхан (К) и морского залива Бакбо (Г) [18]. Для моделирования загрязнения песков стоками нефтепродуктов использованы эмульсии моторного смазочного масла (МСМ). Целью работы является изучение закономерностей сорбции эмульгированных МСМ из водных сред песками.

\section{Методика эксперимента}

Водная эмульсия МСМ была приготовлена смешиванием 1 мл коммерческого продукта в 500 мл дистиллированной воды в делительной воронке при сильном и длительном встряхивании с последующей экстракцией. В опытах использовали фракцию из нижней части.

Концентрацию эмульсии МСМ определяли на приборе «Флюорат 02-5М» фирмы ЛЮМЕКС (Россия) по методике ПНД Ф 14.1:2:4.128-98.

Сорбцию проводили в бюретке диаметром 1 см, куда засыпали некоторое количество песка известной массы, уплотняли аккуратным постукиванием и измеряли высоту слоя сорбента. Через слой сорбента пропускали 25 мл эмульсии моторного масла $\left(\mathrm{C}_{0}=23,70\right.$ мг/л) при постоянной скорости истечения жидкости. Для оценки прочности сцепления пленок моторного масла с песчаным слоем прово- 
дили десорбцию и многократное промывание песка водой до некоторой минимальной концентрации моторного масла в стоке, используя всякий раз 25 мл дистиллированной воды.

Эффективность удерживания песком нефтепродуктов из водного раствора $R$ рассчитывали по относительной разности начальной $\mathrm{C}_{0}$ и конечной $\mathrm{C}_{\text {к }}$ концентраций масла в эмульсии $R=\left(\mathrm{C}_{0}-\mathrm{C}_{\mathrm{K}}\right) / \mathrm{C}_{0}$, или используя массовые соотношения: исходное количество масла $\mathrm{m}_{0}=\mathrm{V}_{0} \cdot \mathrm{C}_{0}=$ $0,025^{\text {л. }} 23,70^{\text {мг/л }}=0,5925$ мг; $\mathrm{m}_{1}-$ сорбированное количество масла; $\mathrm{m}_{2}$ - удаленное в ходе десорбции количество масла; $\mathrm{m}_{3}$ - остаток масла в слое песка после промывания $\left(\mathrm{m}_{3}=\mathrm{m}_{1}-\mathrm{m}_{2}\right)$. В этом случае степень удерживания составит $R_{\text {удер. }}=\mathrm{m}_{3} / \mathrm{m}_{0}$.

Относительная погрешность экспериментов не превышала 5 \%, точки на графиках - средние значения из 3-5 независимых опытов.

\section{Результаты и их обсуждение}

Увеличение высоты фильтрующего слоя $\mathrm{h}$ для всех песков влияет на способность задерживать моторные масла, например, песком Г удерживается более 80 \% нефтепродуктов уже при высоте слоя около 3 см (рис. 1).

На наш взгляд, высокие значения сорбционной способности песков А и Г объясняются их однородным составом и мелкозернистостью (табл. 1).

В песках Б и К частицы более крупных размеров, близкие и более существенные соотношения кварца и корунда, очевидно, поэтому их способно-

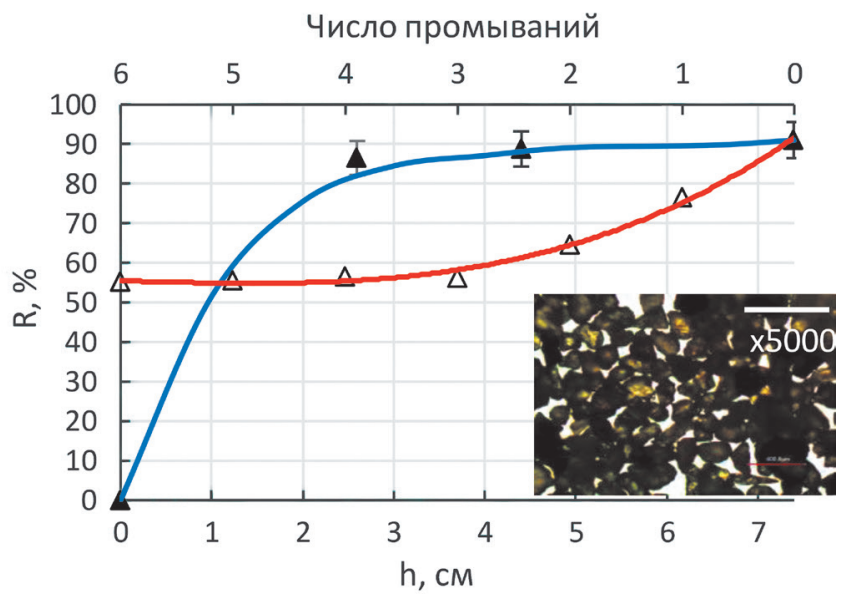

Рис. 1. Формирование пленок масла на песке Г в процессе сорбции $(\Delta)$ и десорбции $(\Delta)$

сти к нефтеудерживанию схожи, но ниже по сравнению с тонкозернистыми песками А и Г.

Процесс отмывания песков в условиях опытов фактически аналогичен таким климатическим изменениям, как дождь, таяние снега и др. (табл. 2).

Видно, что десорбционное промывание песков не приводит к восстановлению исходных свойств твердого сорбента, на песках остается достаточное количество моторного масла. Как правило, в этих результатах обнаруживается те же закономерности, которые проявляются при формировании масляных пленок. Кварцевые мелкозернистые пески

Таблица 1

Некоторые характеристики песков

\begin{tabular}{|c|c|c|c|c|c|}
\hline \multirow{2}{*}{ Песок } & \multirow{2}{*}{$\begin{array}{c}\text { Средний размер, } \\
\text { мм }\end{array}$} & \multirow{2}{*}{$\begin{array}{c}\text { Коэффициент } \\
\text { однородности, \% }\end{array}$} & \multicolumn{2}{|c|}{ Состав, \% (мас.) } & \multirow{2}{*}{$R, \%$} \\
\hline & & & $\mathrm{SiO}_{2}$ & $\mathrm{Al}_{2} \mathrm{O}_{3}$ & \\
\hline A & 0,294 & 53,125 & 98,38 & 1,62 & 84,86 \\
\hline Б & 0,429 & 72,240 & 89,93 & 10,07 & 76,83 \\
\hline$\Gamma$ & 0,241 & 66,919 & 98,99 & 1,01 & 91,05 \\
\hline $\mathrm{K}$ & 0,849 & 61,367 & 89,11 & 10,89 & 79,52 \\
\hline
\end{tabular}

Материальный баланс после 6-ого промывания (слой песка 8 см)

\begin{tabular}{cccc}
\hline Песок & $\mathbf{m}_{\mathbf{1}}, \mathbf{\text { мг }}$ & $\mathbf{m}_{\mathbf{3}}, \mathbf{\text { мг }}$ & $\boldsymbol{R}_{\text {удер. }}, \mathbf{\%}$ \\
\hline A & 0,503 & 0,374 & 63,12 \\
Б & 0,455 & 0,344 & 58,00 \\
Г & 0,539 & 0,296 & 55,09 \\
K & 0,471 & 0,305 & 51,48 \\
\hline
\end{tabular}


А и Г хорошо удерживают нефтепродукты и в процессе их отмывания. Пески Б и К и в этом случае уступают, после промывания на поверхности остается меньшее количества масла, которое удерживалось песками в прямых экспериментах.

Очевидно, что не только состав песка, но и размер зерен и коэффициент однородности песков влияют на процессы сорбции-десорбции по отношению к МСМ. Песок К с самым большим размером частиц и высоким содержанием корунда характеризуется наиболее слабой удерживаемостью для МСМ. Частицы песка К, очевидно, имеют такое соотношение выступов и впадин на микроуровне, принимающих на себя функции адсорбционных центров, которое не благоприятствует образованию пленок масла, а затем - их удерживанию при отмывании.

Как известно, моторные масла представляют смесь углеводородов с различными добавками (антикоррозионными, противоизносными и т.п.) [3, 19]. Компоненты многочисленных добавок и присадок, в свою очередь, каждый по-своему влияют на процессы сорбции и фильтрования [20]. Их стремление к поверхностным взаимодействиям на адсорбционных центрах, энергетически неоднородных по гидрофильно-гидрофобному балансу, очевидно, весьма различно, как различен и их вклад в суммарный эффект.

Для выяснения присутствия молекул углеводородов на поверхности частиц песков проведен анализ ИК-спектра. На рис. 2 для примера пред- ставлены спектры ИК-Фурье до и после сорбции MCM на песке A.

На рис. 2 наблюдаются пики некоторых функциональных групп (таблица 3). После сорбции моторного масла кроме расширения полосы вокруг $3436 \mathrm{~cm}^{-1}$, в диапазоне от 1500 до 2000 см$^{-1}$ возникают новые пики, а также, присутствуют слабые пики функциональных групп Si-O-Si, Si-O-Al, $\mathrm{Si-O}$ и Al-O (в области спектра 518-1084 см ${ }^{-1}$ ) после сорбции, которые вызваны воздействием органических молекул в процессе сорбции.

Поскольку в составе моторного масла находятся в большом количестве ароматические углеводороды, то результаты можно связать с возможностью специфического взаимодействия $\pi$-электронов ароматических колец с активными центрами поверх-

Таблица 3

Функциональные группы на поверхности песка

\begin{tabular}{cl}
\hline \multicolumn{1}{c}{ Пики } & \multicolumn{1}{c}{ Функциональная группа } \\
\hline $3620 \mathrm{~cm}^{-1}$ & Валентные колебания группы -OH \\
$3436 \mathrm{~cm}^{-1}$ & \\
\hline $1084 \mathrm{~cm}^{-1}$ & Валентные колебания групп $\mathrm{Si}-\mathrm{O}$ и Al-O \\
$796 \mathrm{~cm}^{-1}$ & \\
$778 \mathrm{~cm}^{-1}$ & \\
\hline $694 \mathrm{~cm}^{-1}$ & Деформационные колебания групп Si-O \\
$650 \mathrm{~cm}^{-1}$ & и Al-O \\
\hline $1034 \mathrm{~cm}^{-1}$ & $\mathrm{Si}-\mathrm{O}-\mathrm{Si}$ \\
\hline $518 \mathrm{~cm}^{-1}$ & $\mathrm{Si}-\mathrm{O}-\mathrm{Al}$ \\
\hline
\end{tabular}

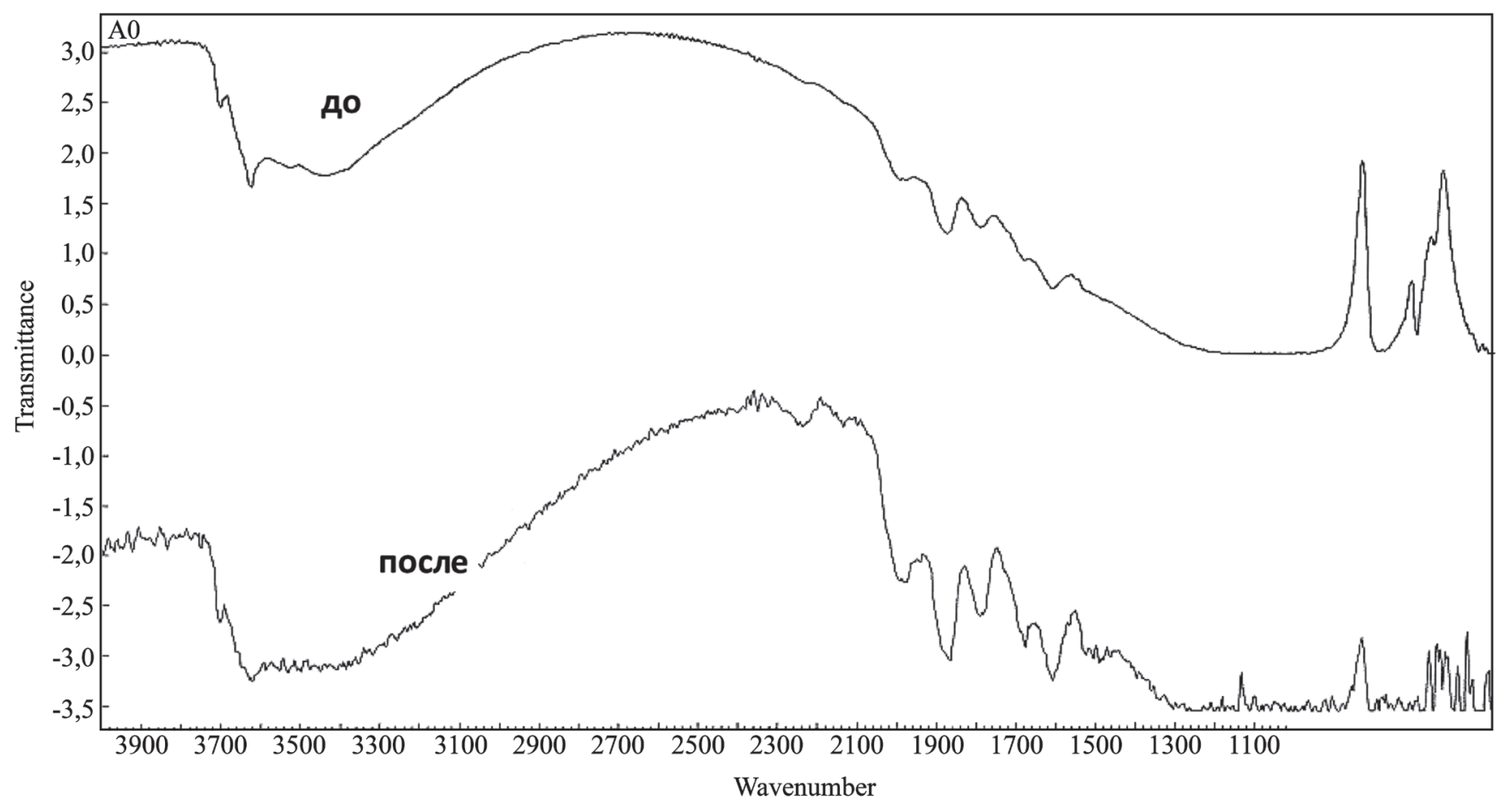

Рис. 2. ИК-спектр песка А до и после сорбции моторного масла 
ности песков с образованием $\pi$-комплексов. Вероятно, что именно такое взаимодействие вносит весомый вклад в природу явлений на поверхности частиц песка.

\section{Выводы}

Результаты коллоидно-химических исследований свидетельствуют, что на поверхности минеральных частиц песка активно выражено удерживание углеводородных фрагментов моторного масла. Нефтеудерживание зависит от кристаллохимических и гранулометрических свойств песков. Оно выше у кварцевых мелкозернистых песков и достигает 85-90\%. Появление в составе песка 10$11 \%$ корунда, укрупнение частиц, изменение однородности состава приводят к снижению способности песков удерживать пленки нефтепродуктов.

\section{Лuтература}

1. Евдокимов А.Ю. Защита окружающей среды в нефтегазовом комплексе. 2020. Т. 294. №3. С. 39-45. DOI: 10.33285/2411-7013-2020-3(294)-39-45.

2. Евдокимов А.Ю., Фукс И.Г., Шабалина Т.Н., Багдасаров Л.Н. Смазочные материалы и проблемы экологии. М.: Нефть и газ. 2000. 423 с.

3. Абросимов А.А. Экология переработки углеводородных систем. М.: Химия, 2002. 608 с.

4. Журавлев В.М., Чернявская Е.Н., Кулагина Т.А., Клименков С.И., Писарева Е.Н. Тез. докл. междунар. науч.-технич. конгресс «Энергетика в глобальном мире». Красноярск. 2010. С. 279-282.

5. Машкин Д.В., Извекова Т.В., Гущуин А.А., Гриневич В.И. Изв. вузов. Химия и химическая технология. 2017. Т. 60, №5. С. 94-99. DOI: 10.6060/ tcct.2017605.5565.

6. Щетнева Я.А. StudArctic Forum. 2016. Т. 1. №1. C. 28-33. DOI: 10.15393/j102.art.2016.121.

7. Чернышев Л.А., Стариева Т.А., Михайленко Д.Ю. Эко-потенциал. 2018. Т. 22. №2. С. 91-95.

8. Bensadok K., Belkacem M., Nezzal G. Desalination. 2007. V. 206. N 1-3. P. 440-448. DOI: 10.1016/j.desal.2006.02.070.

9. Хаснутдинов И.Ш., Сафиулина А.Г., Заббаров Р.Р., Хаснутдинов С.И. Изв. вузов. Химия и химическая технология. 2015. Т. 58. №10. С. 3-20.

10. Филатов Д.А., Овсянникова В.С. Экологический вестник России. 2017. Т. 6. С. 8-12.

11. Демчук И.А., Катин В.Д. Научно-техническое и экономическое сотрудничество стран АТР в XXI веке. 2018. T. 2. C. 21-26.

12. Almojjly A., Johnson D. J., Mandale S., Hilal N. J. Water Process Eng. 2019. V. 27. P. 15-23. DOI: 10.1016/j. jwpe.2018.11.007.

13. Stack L.J., Carney P.A., Malone H.B., Wessels T.K. Ultrasonics Sonochemistry. 2005. V. 12. N 3. P. 153160. DOI: $10.1016 /$ j.ultsonch.2003.10.008.
14. Ejaz Ahmed F., Lalia B.S., Hilal N., Hashaikeh R. Desalination. 2014. V. 344. P. 48-54. DOI: 10.1016/j. desal.2014.03.010.

15. Abbasi M., Mirfendereski M., Nikbakht M., Golshenas M., Mohammadi T. Desalination. 2010. V. 259. P. 169 178. DOI: $10.1016 /$ j.desal.2010.04.013.

16. Tawalbeh M., Al Mojjly A., Al-Othman A., Hilal N. Desalination. 2018. V. 447. P. 182-202. DOI: 10.1016/j. desal.2018.07.029.

17. Яковлева А.А., Нгуен Ч.Т., До В.Т. Изв. вузов. Приклад. химия и биотехнол. 2020. Т. 10, №1. С. 159168. DOI: $10.21285 / 2227-2925-2020-10-1-159-168$.

18. Яковлева А.А., Нгуен Ч.Т. Рос. хим. ж. 2020. Т. 64. №2. C. 80-84. DOI: 10.6060/rcj.2020642.12.

19. Касаткин А.Г. Основные процессы и аппараты химической технологии. М.: ООО Ид «Альянс». 2008. $753 \mathrm{c.}$

20. Русанов А.И. Коллоидный журнал. 2007. Т. 69. №2. C. $149-161$.

\section{References}

1. Evdokimov A. Yu. Environmental aspects of the use of lubricants. Environmental protection in oil and gas complex. 2020. V. 294. N 3. P. 39-45. (in Russian). DOI: 10.33285/2411-7013-2020-3(294)-39-45.

2. Evdokimov A.Yu., Fuchs I.G., Shabalina T.N., Bagdasarov L.N. Lubricants and environmental issues. M.: Neft' i gaz. 2000. 423 p. (in Russian).

3. Abrosimov A.A. Ecology of processing of hydrocarbon systems. M.: Khimiya. 2002. 608 p. (in Russian)

4. Zhuravlev V.M., Chernyavskaya E.N., Kulagina T.A., Klimenkov S.I., Pisareva E.N. Modern possibilities of ensuring environmental safety when treatment of industrial waste. Reports of the international scientific and technical congress "Energy in the global world". Krasnoyarsk. 2010. p. 279-282. (in Russian).

5. Mashkin D.V., Izvekova T.V., Gushchin A.A., Grinevich V.I. Assessment of level pollution of Ivanovo city with heavy metals and oil products. Izv. Vyssh. Uchebn. Zaved. Khim. Khim. Tekhnol. 2017. V. 60. N 5. P. 94-99. (in Russian). DOI: 10.6060/tcct.2017605.5565.

6. Shetneva Ya.A. Environmental impact of fuel and lubricants spills during logging operations. StudArctic Forum. 2016. V. 1. N 1. P. 28-33. (in Russian). DOI: 10.15393/j102.art.2016.121.

7. Chernyshev L.A., Startseva T.A., Mikhailenko D. Yu. Environmental problem of used motor oils. Eco-potential. 2018. Vol. 22. N 2. P. 91-95. (in Russian).

8. Bensadok K., Belkacem M., Nezzal G. Treatment of cutting oil/water emulsion by coupling coagulation and dissolved air flotation. Desalination. 2007. V. 206. N 1-3. P. 440-448. DOI: 10.1016/j.desal.2006.02.070.

9. Khasnutdinov I.Sh., Safiulina A.G., Zabbarov R.R., Khasnutdinov S.I. Methods of oil sludge disposal. Izv. Vyssh. Uchebn. Zaved. Khim. Khim. Tekhnol. 2015. V. 58. N 10. P. 3-20. (In Russian).

10. Filatov D.A., Ovsyannikova V.S. Environmental pollution from petroleum hydrocarbons: problems and solu- 
tions. Ecological Bulletin of Russia. 2017. V. 6. P. 8-12. (In Russian).

11. Demchuk I.A., Katin V.D. Analysis of the state of environmental pollution by oil products. Scientific, technical and economic cooperation of the countries of the Asia-Pacific region in the XXI century. 2018. V. 2. P. 21-26. (In Russian).

12. Almojjly A., Johnson D.J., Mandale S., Hilal N. Optimisation of the removal of oil in water emulsion by using ceramic microfiltration membrane and hybrid coagulation/sand filter-MF. J. Water Process Eng. 2019. V. 27. P. 15-23. DOI: 10.1016/j.jwpe.2018.11.007.

13. Stack L.J., Carney P.A., Malone H.B., Wessels T.K. Factors influencing the ultrasonic separation of oil-in-water emulsions. Ultrasonics Sonochemistry. 2005. V. 12. N 3. P. 153-160. DOI: 10.1016/j.ultsonch.2003.10.008.

14. Ejaz Ahmed F., Lalia B.S., Hilal N., Hashaikeh R. Underwater superoleophobic cellulose/electrospun PVDFHFP membranes for efficient oil/water separation. Desalination. 2014. V. 344. P. 48-54. DOI: 10.1016/j. desal.2014.03.010.

15. Abbasi M., Mirfendereski M., Nikbakht M., Golshenas M., Mohammadi T. Performance study of mullite and mullite-alumina ceramic MF membranes for oily wastewaters treatment. Desalination. 2010. V. 259 P. 169-178. DOI: 10.1016/j.desal.2010.04.013.

16. Tawalbeh M., Al Mojjly A., Al-Othman A., Hilal N. Membrane separation as a pre-treatment process for oily saline water. Desalination. 2018. V. 447. P. 182202. DOI: 10.1016/j.desal.2018.07.029.

17. Yakovleva A.A., Nguyen T.T., Do V.T. Barrier property features of various sands of the South-Western Baikal region in relation to typical environmentally hazardous wastewater // Proceedings of Universities. Applied Chemistry and Biotechnology. 2020. V. 10. N 1. P. 159168. (In Russian) DOI: 10.21285/2227-2925-2020-101-159-168.

18. Yakovleva A.A., Nguyen T.T. On the issue of the barrier qualities of the sands of northern and central Vietnam. Sorption of iron ions (III). Russian Chemical journal. 2020. V. 64. N 2. P. 80-84. (in Russian) DOI: 10.6060/ rcj.2020642.12.

19. Kasatkin A.G. Basic processes and devices of chemical technology. M.: OOO Publisher "Alliance". 2008. 753 p. (in Russian).

20. Rusanov A.I. The essence of a new approach to the equation of monolayer state. Colloid journal. 2007. V. 69. N 2. P. 149-161. (in Russian). 